\title{
Public Preference Analysis and Social Benefits Evaluation of River Basin Ecological Restoration: Application of the Choice Experiments for the Shiyang River, China
}

\author{
Tao Xu, ${ }^{1}$ Qi Ni, ${ }^{2}$ Liu-yang Yao, ${ }^{3}$ Dan Qiao, ${ }^{1}$ and Min-juan Zhao $\mathbb{D}^{2}$ \\ ${ }^{1}$ Management School, Hainan University, Haikou 570228, China \\ ${ }^{2}$ College of Economics and Management, Northwest A\&F University, Yangling, Xianyang, Shaanxi 712100, China \\ ${ }^{3}$ School of International Business, Shaanxi Normal University, Xi'an 710119, China
}

Correspondence should be addressed to Min-juan Zhao; minjuan.zhao@nwsuaf.edu.cn

Received 26 December 2019; Accepted 24 March 2020; Published 22 May 2020

Academic Editor: Giancarlo Consolo

Copyright ( 2020 Tao Xu et al. This is an open access article distributed under the Creative Commons Attribution License, which permits unrestricted use, distribution, and reproduction in any medium, provided the original work is properly cited.

Revealing public preferences regarding the ecological restoration of a river basin and evaluating the associated social benefits provide important references for the development of related policies. Taking the Shiyang River Basin as an example, this study quantified and analyzed the difference in public preferences regarding the ecological restoration of the river basin by the choice experiments method and the random parameters logit (RPL) model. It also evaluated the social benefits of river basin ecological restoration. The results showed that (1) The residents all hoped to improve the ecological environment of the Shiyang River Basin and were willing to bear certain restoration costs. (2) There were significant differences in public preferences for ecological restoration of the river basin. These differences existed between the upper, middle, and lower reaches of the river and between urban and rural residents. (3) The average annual cost of ecological restoration that the basin residents were willing to pay was between 505.833 948.571 RMB yuan, and the total annual benefits of ecological restoration were 381.2 million RMB yuan. Based on these conclusions, the following recommendations were made. First, future ecological and environmental policies should be further combined with public preferences; and even cross-regional ecological compensation can be introduced to balance the interests of different social groups, to win public support. Second, increased water-saving technology in industries and agriculture, residents' awareness of water conservation, and the management of water pollution measures should be promoted in order to improve the ecological environment of the river basin. Third, the budget for the ecological restoration of the Shiyang River Basin should be 381.2 million yuan per year. Costs should be controlled while meeting the restoration goals.

\section{Introduction}

The ecological environment of a river basin is an important material basis for human survival and development. However, with the rapid development of society and the economy, exploitation of human water consumption and water pollution have become increasingly more intense. It has seriously threatened human survival and sustainable social and economic development [1-3]. Using targeted ecological restoration measures to achieve conservation and restoration of the ecological environment of a river basin has become a consensus approach in society $[4,5]$. However, because the ecological restoration of a river basin has strong characteristics of public goods, market failure is often considered to be one of the main causes of ecological deterioration. Necessary administrative measures are required to ensure effective supply [6,7]. Therefore, China has introduced a series of relevant policies and measures for river basin ecological restoration, such as the Action Plan for the Prevention and Control of Water Pollution, the Ecological and Environmental Protection Plan of the Yangtze River Economic Belt, and the Key Management Plan of the Shiyang River Basin. In addition, the Report of the 18th National Congress of the Communist Party of China also made it clear that the development of ecological civilization should be progressively promoted and placed in a prominent position. 
At present, however, the implementation of ecological restoration policies by the government encounters two issues. On the one hand, the public, who has a strong demand for ecological restoration, is also a key force in promoting ecological restoration $[8,9]$. Policies can achieve restoration goals and remain sustainable only if they are actively supported by the public. Otherwise, it is highly likely that social resources will be wasted without being effective [10-12]. However, in practice, because of the asymmetry of governments' access to information, their decision-making often has limitations, which can lead to government failure $[13,14]$. On the other hand, due to the lack of involvement of market mechanisms, ecological governance can bring social benefits without a specific market price to follow. This leads to the lack of a basis for cost-benefit analysis of governance policies, which leaves the rationality of the input-output ratio of governance policies in question $[15,16]$. Therefore, clarifying the public preferences and social benefits of ecological restoration in a river basin and incorporating them into relevant policy development can help compensate for the information asymmetry between policy makers and the public and improve the efficiency of fund allocation for ecological restoration. Doing so also helps correct biases in policy design and enhances its scientific basis, effectiveness and sustainability [17-19].

In terms of quantifying the public preferences and social benefits of ecological restoration, a choice experiment (CE) among the stated preference methods has gradually gained the attention of researchers [20,21]. The theoretical basis of $\mathrm{CE}$ is a random utility approach. The basic assumption is that respondents make choices based on maximizing their utility, thus turning choice problems into utility comparison problems [22, 23]. By combining representative restoration indicators into a clear plan and giving respondents the opportunity to make a trade-off between different restoration indicators, CE provides access to more information on preferences as well as the possibility of a flexible calculation of the social benefits of different levels of restoration. Therefore, it has been considered one of the most promising research methods in the field [24-27].

The current CE studies on river basin ecological restoration include the following. Weber and Stewart [28] calculated the fact that the Albuquerque river basin restoration under the Middle Rio Grande project could bring more than $\$ 150$ USD per household per year of social benefits for the local residents. Zander et al. [29] estimated the benefits of ecological restoration of the Daly River at approximately 6 million USD. Minjuan et al. [30] analyzed the preferences of the residents of the Shiyang River Basin to different restoration indicators. The results showed preference differences among residents ofthe upper, middle, and lower reaches. Shi et al. [11] took the Shaanxi section of the Wei River Basin as an example and showed that there were preference differences between urban and rural residents for ecological restoration of the river basin. Chen et al. [31] explored the differences in public preferences regarding ecological restoration in the Zenne River Basin and their sources. The results showed that urban residents had a strong preference for protecting the biodiversity of the river basin. Tao et al.
[32] used the Heihe River Basin as an example and showed that including the differences between urban and rural residents in ecological restoration could improve the accuracy of social benefit evaluations. Research by Da Costa and Hernandez [33] showed that improving the ecosystem services of the Taravo River could result in a benefit increase of 128 Euros per year for the local residents. The existing studies lend a rich reference value to this article, but two shortcomings exist. First, due to the differences in natural geography in the upper, middle, and lower reaches of a river and different levels of socioeconomic development in urban and rural areas, public preferences regarding ecological restoration in a river basin tend to show large differences $[11,30]$. Currently, there is a lack of consideration of the river basin section and urban versus rural factors in the relevant research. Therefore, it is difficult to provide more effective information on relevant policy development. Second, in the process of social benefits evaluation, the differences in public preference regarding river basin ecological restoration were not paid enough attention, which affected the accuracy and effectiveness of the benefits evaluation results.

In summary, this article used CE to build a hypothetical market. By simulating market trading behavior, the public's WTP for ecological improvement was evaluated [34]. Through econometric analysis, the differences in public preferences were revealed, and the corresponding social benefits were calculated on this basis. The innovative points of this article included (1) focusing on public preference regarding river basin ecological restoration and the group differences, which helped to enhance the scientific basis of policy development and obtain wide public support, (2) incorporating the differences in public preferences into the social benefits evaluation of river basin ecological restoration, which improved the accuracy of the evaluation results and (3) improving the implementation process of CE and the effectiveness of data collection from index system development, questionnaire optimization, and error control.

\section{Research Methods}

Based on the implementation steps proposed by Hensher et al. [23], the research outline of this article was as follows. (1) Historical and present information about the ecological environment of the river basin was collected. (2) The relationship between the ecological environment of the river basin and the productivity and life of the residents was clarified. (3) Based on a pilot survey, focus group interviews, and expert consultations in related fields, an index system was developed to describe the state of the ecological environment of the river basin. (4) Restoration plans using orthogonal experimental design were designed and optimized. (5) A CE questionnaire was generated and further improved through a second round of pilot survey application. (6) A CE survey was conducted through one-to-one interviews on-site to obtain the interviewees' WTP. (7) The utility function of the respondents was estimated, and public preferences and corresponding social benefits were quantitatively analyzed using an econometric model. 
The econometric model used in this article was the random parameters logit (RPL) model, which was used to estimate the residents' utility function. In this model, respondents' preferences for a certain indicator (variable) can be assumed to be heterogeneous, and their coefficient can be specified as random. If a coefficient is specified as random, we can estimate not only its location parameter (mean) but also its scale parameter (standard deviation), and the significance of the scale parameter was used to test for heterogeneity. The preference parameter was set as a distribution and not limited to a set value, which better reflected the reality [35]. Here, respondent $n$ 's utility under river basin ecological restoration scenario $s U_{n s}$ is described as [36]

$$
U_{n s}=V_{n s}+\varepsilon_{n s}=\alpha_{n} \mathrm{ASC}_{n s}+\sum_{i=1}^{K} \beta_{n i} X_{n i s}+\gamma_{n} \mathrm{WTP}_{n s}+\varepsilon_{n s}
$$

In formula (1), $V_{n s}$ represents the measurable portion of the respondent's utility. $\varepsilon_{n s}$ represents the unobservable portion of the respondent's utility. It is generally assumed that the error term of the utility function follows the extreme value type I distribution (i.e., the Gumbel distribution) and the independent and identical distribution. The alternative specific constant (ASC) is associated with the status quo is 1 when the respondent chooses the alternative of not taking ecological restoration measures and 0 otherwise, reflecting the baseline utility that maintaining the current ecological environment can bring to the respondent. $X_{\text {nis }}$ indicates the value of the restoration indicator $i$ when respondent $n$ selects scenario $s . \mathrm{WTP}_{n s}$ indicates respondent $n$ 's WTP for scenario $s . \alpha_{n}, \beta_{n i}$, and $\gamma_{n}$ are the coefficients that reflect respondent $n$ 's preference level, and $\varphi_{n}=\left(\alpha_{n}, \beta_{n}, \gamma_{n}\right)$. Therefore, the probability of respondent $n$ selecting scenario $s$ only among $T$ ecological restoration scenarios is

$$
P_{n s}=\frac{\exp \left(\alpha_{n} \mathrm{ASC}_{n s}+\sum_{i=1}^{K} \beta_{n i} X_{n i s}+\gamma_{n} \mathrm{WTP}_{n s}\right)}{\sum_{t=1}^{T} \exp \left(\alpha_{n} \mathrm{ASC}_{n t}+\sum_{i=1}^{K} \beta_{n i} X_{n i t}+\gamma_{n} \mathrm{WTP}_{n t}\right)=\int e^{V_{n s}\left(\varphi_{n}\right) / \sum_{T} e^{V_{n t}\left(\varphi_{n}\right)} f\left(\varphi_{n}\right) \mathrm{d} \varphi_{n}} .}
$$

Maximum likelihood estimation was used to obtain coefficients $\alpha_{n}, \beta_{n i}$, and $\gamma_{n}$ in the formula above [37]. On this basis, the implicit price (IP) of each indicator was calculated. IP is essentially the marginal rate of substitution of the nonmonetary indicators and monetary indicators. It is also the respondent's marginal WTP for the nonmonetary indicators. It enhances the comparability of public preferences for restoration indicators and the readability of model estimates. For nonmonetary indicator $k$, its IP can be expressed as

$$
\mathrm{IP}_{n i}=\frac{\beta_{n i}}{\gamma_{n}}
$$

In formula (3), $\mathrm{IP}_{n i}$ reflects the IP of restoration indicator $i$ for respondent $n$. That is, when restoration indicator $i$ is raised or lowered by a unit, the monetization effect that can be brought to respondent $n$ will increase or decrease.

Further, the respondent's compensating surplus (CS) was calculated using the following formula [36, 38]:

$$
\mathrm{CS}_{n s}=\frac{1}{\gamma_{n}}\left(Q_{0}-Q_{s}\right)=\frac{1}{\gamma_{n}}\left[\alpha_{n}+\sum_{i=1}^{K} \beta_{n i}\left(X_{i 0}-X_{i s}\right)\right] .
$$

In formula (4), $\mathrm{CS}_{n s}$ is the respondent's CS when the river basin is restored to scenario $s$. $Q_{0}$ is the overall state of the river basin environment when restoration measures are not taken. $Q_{s}$ is the overall state of the river basin environment represented by scenario s. $X_{i 0}$ is the value of restoration indicator $i$ when restoration measures are not taken. $X_{i s}$ is the value of restoration indicator $i$ when the river basin is restored to scenario $s$.

\section{Research Area and Experimental Design}

3.1. Overview of the Study Area. The area studied in this article was the Shiyang River Basin located in Gansu Province. It is one of the four inland rivers in the arid and semiarid areas of northwest China (see Figure 1). In the past few decades, the rapid decline in water quantity and the excessive amount of water allocation for human production and living have caused excessive drainage of the ecological water distribution.As a result, the Shiyang River Basin has faced a series of ecological and environmental issues, such as a decline in the groundwater level and intensification of land desertification [30, 39]. Furthermore, due to untreated industrial and domestic sewage discharge, the water quality in some areas in the basin once dropped to "class V" (the poorest level). In addition, the east, west, and north sides of Minqin County in the lower reach of the Shiyang River Basin are surrounded by two major deserts, the Tengri and Badain Jaran deserts. The average annual precipitation is only approximately $100 \mathrm{~mm}$, and annual evaporation is more than $2600 \mathrm{~mm}$. It is one of the areas with the most serious water shortage in China.

\subsection{Experimental Design}

3.2.1. Indicators. High-quality and sufficient water resources are key for ensuring the function of a river basin ecosystem and an important determining factor for ensuring the effectiveness of the ecological restoration of a river basin. Especially for dry inland river basins, increasing ecological water allocation and improving water quality in the river basin are direct and effective approaches 


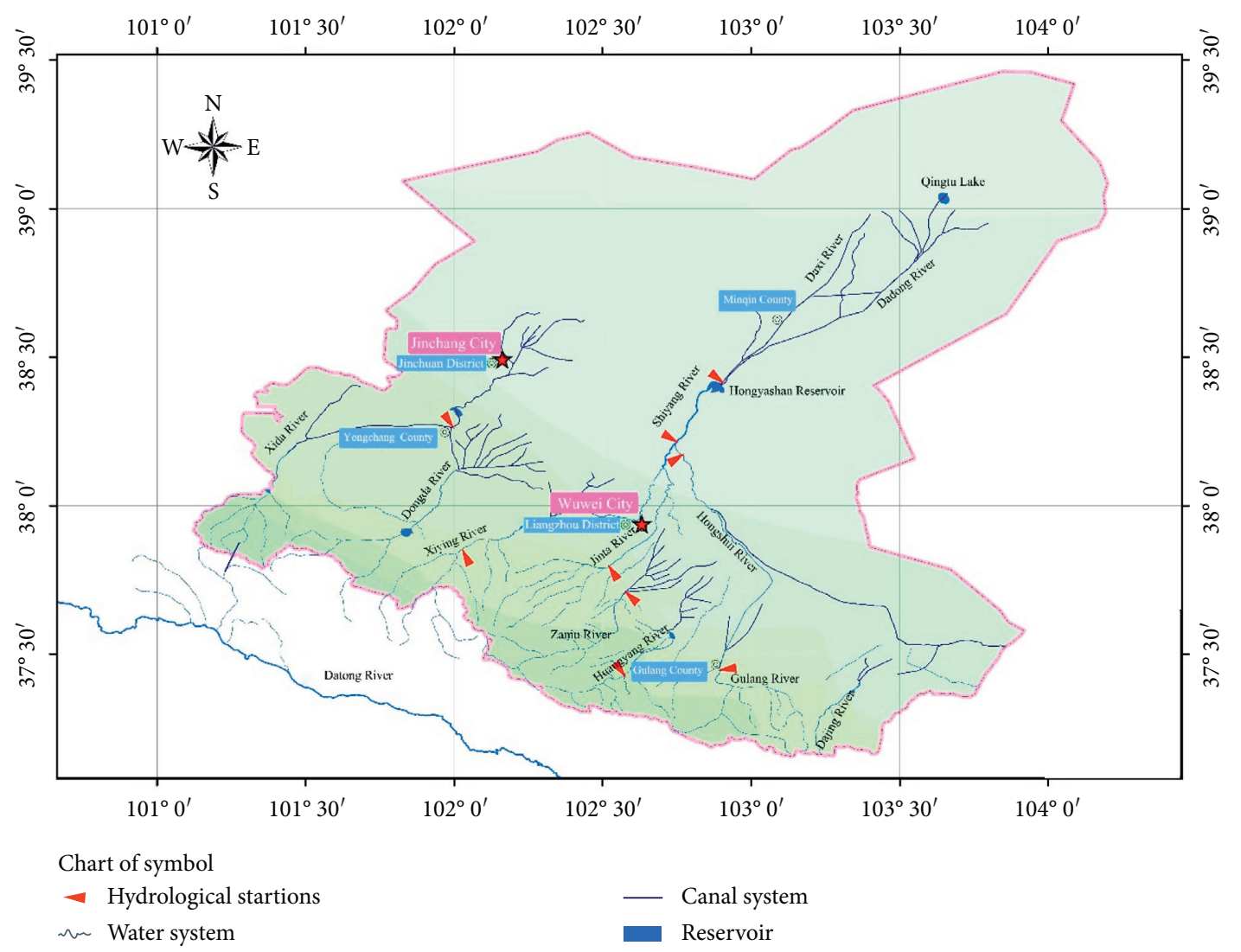

Figure 1: Map of the Shiyang River.

to protect and restore the ecological environment. Therefore, in this study, ecological water allocation and river basin water quality were selected as the restoration indicators. The specific meaning of the indicators and their level settings are as follows.

The first aspect is the ecological water allocation indicator. There are different degrees of water shortage in the upper, middle, and lower reaches of the Shiyang River Basin and significant differences between the basic amount and actual needs of water in different segments of the river $[40,41]$. Therefore, in this paper, the ecological water allocation was further divided into three indicators for each region: upper, middle, and lower reach ecological water allocation. Of course, the increase in ecological water allocation is not generated out of thin air. It is obtained through the conservation of industrial, agricultural, and domestic water (e.g., adoption of water conservation technology and increased awareness of water conservation among residents) as well as improvements in water resource management in the river basin (e.g., scientific allocation, clarifying water rights, and water price regulation) while ensuring the basic water supply of various sectors. The ecological water allocation of different sections was determined based on the historical and current water consumption of the Shiyang River Basin. The total water consumption and potential water savings of each sector in the river basin were estimated. Combined with the opinions of the local administrative departments and experts in related fields, the maximum amount of ecological water allocation was calculated. Finally, the total amount was allocated according to the existing ecological water allocation in each section (shown in Table 1). To ensure that the ecological water allocation indicator was easy to understand for the respondents, the general ecological effects associated with the increase in ecological water allocation were described during the survey. Based on the irrigation quota of $215 \mathrm{~m}^{3} / \mathrm{Mu}$ for artificial shelterbelt forests, an increase of 10 million $\mathrm{m}^{3}$ water allocation could irrigate an additional 465,000 Mu of shelterbelt forests each year.

The second indicator was water quality. Hongyashan Reservoir is Asia's largest artificial reservoir in a desert, known as the "pearl of the sea;" it has many functions such as flood control, drought prevention, aquaculture, and tourism. In addition, the reservoir is located in the lower reach of the Shiyang River Basin and can reflect water pollutions issue in the whole river basin. Therefore, it has been a social focus point and conducive for CE surveys. According to the Shiyang River Basin Water Resources Bulletin, the water quality for Hongyashan Reservoir decreased to class $\mathrm{V}$ in approximately 2004. After restoration, water quality improved to class IV but remained heavily polluted. Combined with the opinions of the Shiyang River Basin management department and experts in related fields, it was determined that an ideal goal was to raise the water quality to class III through further pollution prevention and control; this goal was achievable. 
TABLE 1: Ecological restoration indicators for the Shiyang River Basin.

\begin{tabular}{|c|c|c|}
\hline Restoration indicators & Meaning of the indicators & Levels \\
\hline \multirow{2}{*}{$\begin{array}{l}\text { Upper reach ecological } \\
\text { water allocation }\end{array}$} & \multirow{2}{*}{$\begin{array}{l}\text { The upper reach ecological water allocation included the basic water needs for } \\
\text { the forest and grasslands in the upper reach of the Shiyang River within Gulang } \\
\text { County and the irrigation of the artificial shelterbelt forests along the desert } \\
\text { edges }\end{array}$} & $\begin{array}{l}7 \text { million } \mathrm{m}^{3}(+0) \\
11 \text { million } \mathrm{m}^{3}(+4)\end{array}$ \\
\hline & & 15 million $\mathrm{m}^{3}(+8)$ \\
\hline \multirow{2}{*}{$\begin{array}{l}\text { Middle reach ecological } \\
\text { water allocation }\end{array}$} & \multirow{2}{*}{$\begin{array}{l}\text { The middle reach ecological water allocation mainly included the basic water } \\
\text { needs and irrigation for the natural grasslands and shrubs along the middle } \\
\text { reach of the Shiyang River in Liangzhou District, the irrigation of the artificial } \\
\text { shelterbelt forests, and replenishment of groundwater }\end{array}$} & $\begin{array}{l}95 \text { million } \mathrm{m}^{3}(+0) \\
115 \text { million } \mathrm{m}^{3}(+20)\end{array}$ \\
\hline & & 135 million $\mathrm{m}^{3}(+40)$ \\
\hline \multirow{2}{*}{$\begin{array}{l}\text { Lower reach ecological } \\
\text { water allocation }\end{array}$} & \multirow{2}{*}{$\begin{array}{l}\text { The lower reach ecological water allocation mainly included the basic water } \\
\text { needs of natural dry-land vegetation (Russian olive, salt cedar, and Haloxylon } \\
\text { ammodendron) in the Minqin Basin, irrigation for the artificial shelterbelt } \\
\text { forests of the oasis, groundwater replenishment, and ecological water } \\
\text { supplement to Qingtu Lake located near the end of the Shiyang River }\end{array}$} & $\begin{array}{l}100 \text { million } \mathrm{m}^{3}(+0) \\
130 \text { million } \mathrm{m}^{3}(+40)\end{array}$ \\
\hline & & 160 million $\mathrm{m}^{3}(+60)$ \\
\hline $\begin{array}{l}\text { Hongyashan } \mathrm{Re} \\
\text { water quality }\end{array}$ & $\begin{array}{l}\text { The water quality of Hongyashan Reservoir refers to the water quality class. } \\
\text { Clean water is the basis of human life and the survival of animal and plant } \\
\text { populations (fish, waterbirds, plants, etc.). It also serves recreational functions } \\
\text { such as swimming and fishing }\end{array}$ & Class IV; class III \\
\hline WTP & $\begin{array}{l}\text { To improve the ecological environment of the Shiyang River Basin and } \\
\text { regional ecological security level, the annual willingness of each family will be } \\
\text { paid in the next } 10 \text { years }\end{array}$ & $\begin{array}{l}0 \text { yuan; } 50 \text { yuan; } 100 \text { yuan; } \\
200 \text { yuan; } 300 \text { yuan }\end{array}$ \\
\hline
\end{tabular}

Another indicator was WTP. Protection and restoration of the ecological environment of the river basin require governance measures, which are associated with costs and require the residents to pay some necessary costs. Of course, these costs are not necessarily in the form of cash. They might be passed on to food prices, taxes, and tickets to recreational sites in various forms, such as rising water prices, increasing pollution control and developing ecological protection areas. They are ultimately reflected in increases in cost of living. The levels of WTP were determined mainly based on a pilot survey using the contingent valuation method (CVM), and we found that most of the residents in the survey were willing to pay less than 300 yuan.

In addition, there are two points to note about the indicator values. First, the levels of the indicators were set considering the "equal-distant principle" and "rounding principle" to avoid causing cognitive barriers for the respondents. The number of levels was randomly generated on the basis of meeting these principles. Second, the ecological water allocation and the water quality were the levels expected to be achieved in 10 years. It was assumed that the change in the indicator values was continuous during the 10 years.

3.2.2. Questionnaire Design. Based on prior research, each $\mathrm{CE}$ questionnaire provided the respondents with three choice sets (i.e., every three choice sets were an experiment requiring each respondent to make three separate choices). Each choice set included three alternatives [42, 43]. Figure 2 shows one of the choice sets. "Alternative 0" represents no restoration measures. "Alternative 1" and "Alternative 2" represent different levels of management measures.

As shown in Table 1, based on the indicators and their level values, there were 216 possible alternatives
$(3 * 3 * 3 * 2 * 4)$ (The level of each indicator corresponding to " 0 " WTP is a fixed value, that is, the state when no governance measures are taken. Therefore, only four levels of the WTP are entered into the permutation and combination.), 23,220 possible choice sets $\left(\mathrm{C}_{216}^{2}\right)$, and $2.696 * 10^{8}$ possible $\mathrm{CE}$ questionnaires $\left(\mathrm{C}_{23220}^{2}\right)$. If all the possible $\mathrm{CE}$ questionnaires were tested, it would take a massive amount of labor and resources and would be difficult to achieve [44, 45]. Therefore, this article used "Ngene 1.1.1" to carry out an orthogonal experimental design. Some representative CE questionnaires were selected based on orthogonality. Finally, a total of $12 \mathrm{CE}$ questionnaires containing 36 choice sets were generated. The results of the efficiency measure of the orthogonal experiment had a D-error of 0.000504 and an A-error of 0.034161 (Both $\mathrm{D}$-error and A-error are derived from the progressive variance covariance matrix. The $\mathrm{D}$-error takes the determinant of the matrix, and the A-error takes the trace of the matrix. The ideal experimental design can achieve the minimization of the two.).

The following explanations need to be made regarding the CE questionnaires. First, in "Alternative 1" and "Alternative 2," at least one indicator has been improved compared to "Alternative 0." Second, there is no difference in terms of priority between the two alternatives with restoration measures. Third, because the focus of restoration measures may be different, the indicator values in the highpayment alternative are not necessarily all higher than the low-payment alternative. Fourth, if the values of the indicators in one restoration alternative are all higher than in the other alternative, the amount of payment for that alternative is also higher than the other (For a normal commodity, if all the indicators of one commodity are better than the other, then its price should also be higher than the other. Therefore, if the choice sets obtained from "Ngene 1.1.1" were not in line with common sense, they had to be adjusted.). Based on 


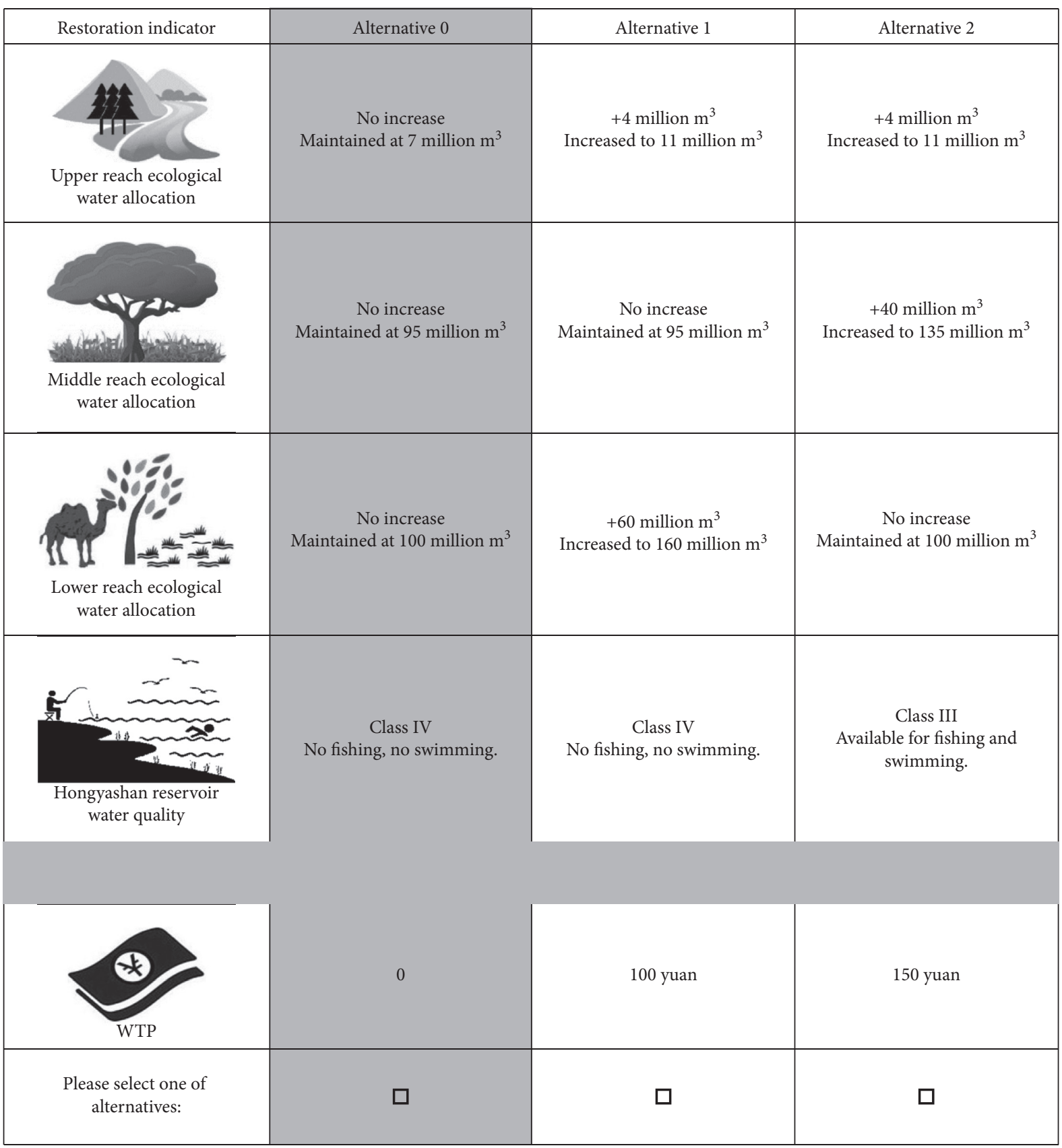

Figure 2: Example of a choice set.

these guidelines, the rationality of each choice set and $\mathrm{CE}$ questionnaire was examined.

3.2.3. Experiment Optimization. The accuracy of the respondents' understanding of the questionnaire and access to appropriate information are keys to the success of $\mathrm{CE}$ $[32,46]$. Therefore, the following measures were taken to optimize the experiment. First, the CE questionnaire was designed with a combination of graphics and text (as shown in Figure 2), making the policy scenarios more visual.
Consequently, the experiments were more interesting and easier for the respondents to understand. Second, before the formal survey, combining the results from the pilot survey, the description of indicators was further optimized to make sure that the respondents could accurately understand the questionnaire. Third, at the end of the survey, the respondents were asked to self-evaluate their understanding level and attitude toward completion of the questionnaires. The investigators then evaluated the degree of cooperation, understanding, and rigor of the respondents to provide a basis for distinguishing the effectiveness of the CE. Fourth, 
before the formal survey, the investigators were professionally trained. The operation process and precautions of CEs were explained in detail to ensure the standardization of the CE survey.

\section{Data and Variable Description}

The data in this paper were derived from the field visit and survey of urban and rural residents in the Shiyang River Basin in August 2016. The field research took a stratified random sample, and the survey covered urban residents along the main streets of each urban area. The survey of rural residents covered the towns and villages with different populations, economic situations, and distances from the county center and river and groundwater levels. Ultimately, a total of 760 questionnaires were obtained, of which 736 were valid.

From the existing research, the upper, middle, and lower reaches of the basin are often different in terms of the natural environment and social economic development. Urban and rural residents are also very different in their ability of payment and environmental awareness. These factors are also important factors influencing the ecological management preferences and WTP among the residents in a river basin $[32,47,48]$. Therefore, we divided the respondents in the survey into 6 groups according to the basin sections as well as their urban and rural categories, as shown in Table 2.

The CE questionnaires was more complex than traditional surveys and not as easy for respondents to understand. Additionally, the experiments simulated a family-based purchase decision. Therefore, the field study required the investigators to confirm whether the respondent was the head of the household or whether he or she could make decisions on behalf of the family prior to the experiment. This was one of the main reasons that the proportion of male respondents in the sample was higher than the proportion of female respondents. In addition, it can be seen from the sample descriptive statistics that the average age of rural residents was higher than that of urban residents. This finding was consistent with the youth and adult labor outflow faced by rural areas of China. Urban respondents' education levels were mainly high school, secondary school, or three-year college. Rural respondents were mainly primary or junior high school graduates. The size of households was largely $4 \sim 5$ people, and the proportion of the labor force was between 0.53 and 0.65 .

In this paper, the restoration alternatives indicators selected by respondents were counted, as shown in Table 3 . The mean ecological water allocation and water quality were improved relatively to the current situation. This finding indicated that the residents hoped to improve the ecological environment of the basin through ecological water allocation and improving water quality. In addition, the mean ecological water distribution, water quality and WTP showed certain differences between different sample groups.

\section{Econometric Analysis and Benefits Evaluation}

5.1. Results of RPL Model Estimation. In this paper, the RPL model was estimated using Halton draws with 500 simulations in Stata $15.0[49,50]$ (In our study, we estimated the RPL model over a range of draws, respectively (e.g., 50, $100,200,300,400,500,800$, and 1000 draws), and we found that with 500 times, the results showed stability.). The results are shown in Table 4 . For the model estimation, the coefficients of the ecological water allocation and water quality were specified as random, and we could estimate their means and standard deviations. The coefficients of ASC and WTP were specified as fixed, and only their means were estimated. In previous presurveys, we found that most respondents had a strong willingness to pay to improve the local ecological environment, and, in formal surveys, we also found that only $6.79 \%$ did not choose alternatives with restoration measures. Therefore, we assumed that respondents had a preference consistency between alternatives with restoration measures and without restoration measures, and the coefficient of ASC was specified as fixed, which is consistent with many studies $[37,46]$. The coefficient of WTP was specified as fixed, because we assumed that WTP was inversely proportional to the level of respondents' utility, which means that they were constrained by the budget line when choosing alternatives, a commonly observedphenomenon [23, 51, 52]. From the overall fitting of the model, the likelihood ratios of the six samples all reached a significance level of $1 \%$, indicating that the econometric model was overall statistically significant.

From the mean estimates of ecological water allocation, we observed obvious preference differences between the residents of the upper, middle, and lower reaches. However, the common characteristic was that most residents in the survey wanted the ecological water allocation in their section to increase, showing a strong inclination toward "self-interest." At the same time, it was found that (1) for upper reach urban residents the mean estimation of the ecological water allocation in the upper and middle reaches of the river was not significant, indicating that the increase in ecological water allocation in any section would not increase their utility. (2) Middle reach urban residents hoped to increase the ecological water allocation in not only the middle reach but also the lower reach. The reason might be that changes in the lower reach ecological environment would affect the quality of life of middle reach residents to some extent (e.g., sandstorms mainly originate from the lower reach, etc.). (3) Lower reach urban residents hoped to increase the ecological water allocation in not only the lower reach but also the upper reach. The reason might be that the increase in ecological water allocation in the upper reach would help to restore the upper reach vegetation cover and improve water conservation capacity. In terms of the water quality of Hongyashan Reservoir, the mean values for the six groups of samples were estimated to be negatively significant at a $5 \%$ level or above, indicating that the water quality of the reservoir improving from class IV to class III would be beneficial for all residents in the basin.

From the mean estimates of ASC, all results except lower reach urban residents were negatively significant at a $5 \%$ level or above. The residents of the Shiyang River Basin had a strong tendency to take ecological restoration measures. In terms of the water quality of Hongyashan Reservoir, the estimated mean values for the six groups of samples were all 
TABLe 2: Descriptive statistics of the sample.

\begin{tabular}{lcccccc}
\hline \multirow{2}{*}{ Project } & \multicolumn{2}{c}{ Upper reach } & \multicolumn{2}{c}{ Middle reach } & \multicolumn{2}{c}{ Lower reach } \\
& Urban & Rural & Urban & Rural & Urban & Rural \\
\hline Gender & $0.495(0.500)$ & $0.655(0.475)$ & $0.677(0.468)$ & $0.730(0.444)$ & $0.680(0.467)$ & $0.719(0.449)$ \\
Age (years) & $35.187(10.172)$ & $46.294(13.034)$ & $39.126(12.713)$ & $43.865(11.284)$ & $36.718(11.412)$ & $51.281(10.767)$ \\
Level of education (years) & $12.000(3.464)$ & $7.769(4.167)$ & $12.291(3.561)$ & $9.021(3.338)$ & $12.913(2.903)$ & $8.460(3.283)$ \\
Number of families/persons & $4.159(1.298)$ & $4.765(1.633)$ & $4.173(1.375)$ & $4.660(1.298)$ & $4.068(1.331)$ & $3.986(1.474)$ \\
Labor input & $0.534(0.210)$ & $0.566(0.212)$ & $0.571(0.230)$ & $0.571(0.210)$ & $0.621(0.197)$ & $0.656(0.248)$ \\
Number of samples & 107 & 119 & 127 & 141 & 103 & 139 \\
\hline
\end{tabular}

Note: (a) In gender statistics, males are equal to 1, females are equal to 0; (b) data are the mean (standard deviation).

TABLE 3: Variable descriptive statistics.

\begin{tabular}{|c|c|c|c|c|c|c|}
\hline \multirow{2}{*}{ Variable } & \multicolumn{2}{|c|}{ Upper reach } & \multicolumn{2}{|c|}{ Middle reach } & \multicolumn{2}{|c|}{ Lower reach } \\
\hline & Urban & Rural & Urban & Rural & Urban & Rural \\
\hline $\begin{array}{l}\text { Upper reach ecological water } \\
\text { allocation }\end{array}$ & $3.676(3.301)$ & $3.518(3.337)$ & $3.643(3.353)$ & 3.439 (3.339) & $3.728(3.362)$ & $2.974(3.244)$ \\
\hline $\begin{array}{l}\text { Middle reach ecological water } \\
\text { allocation }\end{array}$ & $\begin{array}{c}16.760 \\
(16.339)\end{array}$ & $17.143(16.817)$ & $\begin{array}{c}18.530 \\
(16.605)\end{array}$ & $\begin{array}{c}20.760 \\
(16.716)\end{array}$ & $16.570(16.745)$ & $15.156(16.424)$ \\
\hline $\begin{array}{l}\text { Lower reach ecological water } \\
\text { allocation }\end{array}$ & $\begin{array}{c}26.822 \\
(25.234)\end{array}$ & $25.462(25.132)$ & $\begin{array}{c}27.008 \\
(24.343)\end{array}$ & $\begin{array}{c}23.302 \\
(24.187)\end{array}$ & $33.301(24.669)$ & $27.770(25.759)$ \\
\hline $\begin{array}{l}\text { Hongyashan Reservoir water } \\
\text { quality }\end{array}$ & $3.433(0.496)$ & $3.398(0.490)$ & $3.367(0.483)$ & $3.447(0.498)$ & $3.437(0.497)$ & $3.434(0.496)$ \\
\hline WTP & $\begin{array}{l}132.087 \\
(99.050) \\
\end{array}$ & $\begin{array}{c}130.252 \\
(102.747) \\
\end{array}$ & $\begin{array}{l}133.465 \\
(97.412) \\
\end{array}$ & $\begin{array}{l}126.841 \\
(97.976) \\
\end{array}$ & $\begin{array}{c}145.955 \\
(105.181) \\
\end{array}$ & $\begin{array}{c}116.787 \\
(100.150)\end{array}$ \\
\hline
\end{tabular}

Note: (a) Unit of ecological water allocation is million m3; (b) class IV water quality is equal to 4, class III water quality is equal to 3 ; (c) the unit for WTP is the yuan; (d) data are the mean (standard deviation).

TABLE 4: Results of RPL model estimation.

\begin{tabular}{|c|c|c|c|c|c|c|}
\hline \multirow{2}{*}{ Variable } & \multicolumn{2}{|c|}{ Upper reach } & \multicolumn{2}{|c|}{ Middle reach } & \multicolumn{2}{|c|}{ Lower reach } \\
\hline & Urban & Rural & Urban & Rural & Urban & Rural \\
\hline M (upper reach ecological water allocation) & 0.094 & $0.457^{* *}$ & -0.048 & -0.020 & $0.112^{*}$ & -0.116 \\
\hline M (middle reach ecological water allocation) & -0.013 & -0.030 & $0.036^{* *}$ & $0.078^{* *}$ & 0.004 & -0.001 \\
\hline M (lower reach ecological water allocation) & 0.013 & 0.020 & $0.024^{* *}$ & -0.002 & $0.060^{* * *}$ & $0.050^{* * *}$ \\
\hline M (Hongyashan Reservoir water quality) & $-2.295^{* * *}$ & $-10.088^{* *}$ & $-3.130^{* * *}$ & $-2.770^{* * *}$ & $-2.144^{* * *}$ & $-4.134^{* * *}$ \\
\hline M ASC & $-3.125^{* * *}$ & $-4.884^{*}$ & $-2.697^{* * *}$ & $-3.205^{* * *}$ & -0.613 & $-1.971^{* *}$ \\
\hline M (WTP) & $-0.008^{* * *}$ & $-0.031^{* *}$ & $-0.012^{* * *}$ & $-0.016^{* * *}$ & $-0.007^{* * *}$ & $-0.018^{* * *}$ \\
\hline SD (upper reach ecological water allocation) & $0.523^{* * *}$ & $2.065^{* *}$ & $0.383^{* * *}$ & $0.454^{* * *}$ & $0.287^{* * *}$ & $0.399^{* * *}$ \\
\hline SD (middle reach ecological water allocation) & $0.071^{* * *}$ & $-0.328^{* *}$ & $-0.077^{* *}$ & $0.144^{* * *}$ & $0.056^{* *}$ & $0.090^{* * *}$ \\
\hline SD (lower reach ecological water allocation) & $-0.054^{* * *}$ & $0.149^{* *}$ & $-0.043^{* * *}$ & $0.063^{* * *}$ & $0.063^{* * *}$ & $0.092^{* * *}$ \\
\hline SD (Hongyashan Reservoir water quality) & $4.546^{* * *}$ & $23.404^{* *}$ & $4.490^{* * *}$ & $4.536^{* * *}$ & $3.350^{* * *}$ & $5.451^{* * *}$ \\
\hline Log likelihood & -244.744 & -276.445 & -235.291 & -252.323 & -331.590 & -314.002 \\
\hline $\operatorname{LR~chi~}^{2}(4)$ & $79.390^{* * *}$ & $64.490^{* * *}$ & $59.070^{* * *}$ & $144.720^{* * *}$ & $82.830^{* * *}$ & $128.53^{* * *}$ \\
\hline
\end{tabular}

${ }^{*},{ }^{* *}$, and ${ }^{* * *}$ represent $10 \%, 5 \%$, and $1 \%$ significance levels, respectively.

negatively significant at a $5 \%$ level or above. The payment amount was inversely proportional to the level of utility of residents, indicating that the residents in the survey did not randomly choose the restoration plan without any considerations. It also showed that the CE did well in simulating the consumer behavior of the residents in the survey.

From the standard deviation estimates of the coefficients of the ecological water allocation and the water quality of Hongyashan Reservoir, which were specified as random, we saw that they all passed the $5 \%$ significance test in six models. This result indicated that respondents had a preference heterogeneity for each ecological indicatorand that the assumption of preference with the RPL model was closer to the real situation.

5.2. IP Measurement. The estimation results of the RPL model above could reflect whether respondents had a preference for certain restoration indicators. Further IP analysis could quantify the marginal willingness of the residents to pay for the unit change in the restoration indicators and reveal the degree of preference. Table 5 shows the IP of the restoration indicators with a significant estimate at the $10 \%$ significance level or greater. 
TABLE 5: Implicit prices for restoration indicators.

\begin{tabular}{lccccc}
\hline \multirow{2}{*}{ Implicit price } & \multicolumn{2}{c}{ Upper reaches } & \multicolumn{2}{c}{ Middle reaches } & \multicolumn{2}{c}{ Lower reaches } \\
& Urban & Rural & Urban & Rural & Urban \\
\hline Upper reach ecological water allocation & - & 14.917 & - & - & 16.122 \\
Middle reach ecological water allocation & - & - & 2.932 & 5.031 & - \\
Lower reach ecological water allocation & - & - & 1.948 & - & - \\
Hongyashan Reservoir water quality & 278.047 & 329.475 & 257.432 & 178.207 & 309.197 \\
\hline
\end{tabular}

TABLE 6: Compensating surplus and benefits of ecological restoration.

\begin{tabular}{|c|c|c|c|c|c|c|}
\hline \multirow{2}{*}{ Items } & \multicolumn{2}{|c|}{ Upper reaches } & \multicolumn{2}{|c|}{ Middle reaches } & \multicolumn{2}{|c|}{ Lower reaches } \\
\hline & Urban & Rural & Urban & Rural & Urban & Rural \\
\hline Compensating surplus calculation & 677.500 & 600.903 & 725.583 & 568.438 & 948.571 & 505.833 \\
\hline Number of households (10,000 households) & 6.686 & 12.060 & 15.199 & 17.890 & 2.459 & 5.560 \\
\hline Total benefits $(10,000$ yuan) & 4529.765 & 7246.893 & 11028.141 & 10169.347 & 2332.537 & 2812.433 \\
\hline
\end{tabular}

In detail, (1) the IP of upper reach ecological water allocation was relatively high. For the increase of 1 million $\mathrm{m}^{3}$ ecological water allocation, upper and lower reach urban residents were willing to pay 14.917 yuan and 16.122 yuan, respectively. The reason might be that the quantity of ecological water in the upper reach was relatively small, and the total amount of payment was low, resulting in respondents being insensitive to the price of ecological water allocation in the upper reach. (2) For every 1 million $\mathrm{m}^{3}$ increase in the ecological water allocation in the middle reach, the middle reach urban residents were willing to pay 2.932 yuan, which was lower than the 5.031 yuan the rural residents were willing to pay. The reason might be that the middle reach rural residents were relatively far away from the river. In comparison, the urban residents were closer to the desert and had a stronger sense of ecological crisis. (3) For every 1 million $\mathrm{m}^{3}$ increase in ecological water allocation in the lower reach, the middle reach urban residents, lower reach urban, and rural residents were willing to pay 1.948, 8.631 and 2.773 yuan, respectively. The marginal WTP of lower reach urban residents was higher than that of rural residents. The reason might be that, on the one hand, the environmental deterioration caused by water shortages in the lower reach areas had been very prominent, and the urban and rural residents had a strong sense of ecological crisis (which was different from the middle reach areas). On the other hand, compared to the rural residents, urban residents had a higher ecological awareness and ability to pay. (4) For the water quality of Hongyashan Reservoir improving from class IV to class III, the marginal WTP of the residents in the survey showed a large difference. The marginal WTP of the upper reach residents was higher than that of the middle and lower reaches. The reason might be that upper reach residents were less concerned about ecological water allocation and more willing to pay for improved water quality. The residents in the middle and lower reaches paid attention to the increase in ecological water allocation and water quality improvement. They needed to balance between the two based on their limited ability to pay. The marginal WTP of the lower reach residents was higher than that of the middle reach residents. The reason might be that Hongyashan Reservoir is located in the lower reach area, and its water quality has a greater impact on the productivity and life of the lower reach residents. Therefore, lower reach residents' marginal WTP was also higher.

5.3. CS Calculation. The CS reflected annual fees that the households in the survey were willing to pay for the increase in ecological water allocation and improvement in water quality of Hongyashan Reservoir. In this study, it was assumed that the restoration indicators could improve the optimal level design; the results of the CS calculation are shown in Table 6 . It can be seen that there are some differences in the CS of the residents in the survey. The reason might be that their ecological consciousness and ability to pay were different. Further, according to the number of urban and rural households in the Shiyang River Basin from the 2017 Gansu Statistical Yearbook (data at the end of 2016), the total CS of the urban and rural residents in each basin section was calculated. Summing the CS of each section indicated that the total benefits of the ecological restoration of the Shiyang River Basin each year were 381.2 million yuan.

\section{Conclusion and Discussion}

This article used the inland river basin of the Shiyang River as an example. Using a CE questionnaire design, field survey, and RPL model estimation, the social benefits of the ecological restoration of the river basin were analyzed. The main conclusions are as follows. (1) The residents in the survey hoped to improve the ecological environment of the Shiyang River Basin by increasing ecological water allocation and improving the water quality of Hongyashan Reservoir and were willing to bear certain restoration costs. (2) There were clear differences in public preferences for ecological restoration of the river basin. These differences occurred not only between the the urban and rural residents but also among the upper, middle, and lower reaches, providing strong evidence for building a cross-regional ecological compensation mechanism. (3) The annual expenses that the 
residents in the survey were willing to pay for ecological restoration of the basin were roughly distributed between 505.833 and 948.571 yuan. Based on these numbers, the total annual social benefits of ecological restoration were 381.2 million yuan.

Based on the analysis and conclusions above, the following recommendations should be considered. First, the design of ecological restoration policies in the river basin should consider more public preferences, taking into account the interests of urban and rural residents in the upper, middle, and lower reaches. When necessary, crossregional ecological compensation can be introduced to balance the interests of different social groups to gain more public support. Second, efforts to introduce advanced industrial water-saving technology, promote agricultural water-saving irrigation technology, improve water-saving awareness of river basin residents and strictly control agricultural nonpoint source pollution and urban sewage discharge should be further increased. Through the joint action of various management measures, the ecological water allocation in the Shiyang River Basin should be increased and the water quality of Hongyashan Reservoir should be improved. Third, ecological management measures in the Shiyang River Basin should be implemented. If the annual investment of up to 381.2 million yuan can be made, ecological water allocation in the upper, middle and lower reaches will increase by 8 million $\mathrm{m}^{3}, 40$ million $\mathrm{m}^{3}$, and 60 million $\mathrm{m}^{3}$, respectively, in 10 years. At the same time, the water quality will improve to class III. These measures are reasonable and effective.

\section{Data Availability}

The (respondents' WTP and characteristics) data used to support the findings of this study are currently under embargo while the research project was completed. Requests for data (18 months) after publication of this article should be made to Xu Tao (xutao_2013@outlook.com).

\section{Conflicts of Interest}

The authors declare that there are no conflicts of interest regarding the publication of this paper.

\section{Acknowledgments}

Thanks are due to the National Natural Science Foundation of China Major Research Project: "The construction of a natural resource management system in the context of ecological civilization development: full value assessment and multicenter approach" (15ZDA052). The authors acknowledge Hainan Philosophy and Social Science Foundation Young Scientist Grant: "social benefit assessment and long-term mechanism research on water pollution control in Hainan Province" (HNSK (QN) 19-23). Hainan University Research Start-Up Grant Project is also gratefully acknowledged: "public preferences and social welfare research on river basin ecological restoration" (KYQD (SK) 1917).

\section{References}

[1] S. Dong-yuan, J. Yan-zhao, L. Yuan-hong, and H. Xiangquan, "Patterns of water resources management in Arid inland river basins," China Rural Water and Hydropower, no. 1, pp. 80-84, 2015, in Chinese.

[2] P. Ghisellini, C. Cialani, and S. Ulgiati, "A review on circular economy: the expected transition to a balanced interplay of environmental and economic systems," Journal of Cleaner Production, vol. 114, pp. 11-32, 2016.

[3] S. Heng-tong, S. Dang-chen, X. Tao, and Z. Min-juan, "The influence mechanism of ecological value cognition on farmers' willingness to participate in ecological management: an example from weihe basin in Shaanxi Province," China Rural Survey, no. 2, pp. 68-80, 2017, in Chinese.

[4] C. J. Vörösmarty, P. B. McIntyre, M. O. Gessner et al., "Global threats to human water security and river biodiversity," Nature, vol. 467, no. 7315, pp. 555-561, 2010.

[5] W. Si-kai, Z. Ting-ting, G. Yu, Z. Feng, and Z. Ping, "Comprehensive management of the rhine river basin and its experiences," Resources and Environment in the Yangtze Basin, vol. 27, no. 1, pp. 215-224, 2018, in Chinese.

[6] R. Muradian and L. Rival, "Between markets and hierarchies: the challenge of governing ecosystem services," Ecosystem Services, vol. 1, no. 1, pp. 93-100, 2012.

[7] C. Jiam-bin and C. Mao, "On the research of the establishment of government responsibility mechanism in the valley of lakes' ecological management," Journal of Xiangtan University (Philosophy and Social Sciences), vol. 40, no. 3, pp. 19-23, 2016, in Chinese.

[8] M. A. Berry and D. A. Rondinelli, "Proactive corporate environmental management: a new industrial revolution," Academy of Management Perspectives, vol. 12, no. 2, pp. 3850, 1998.

[9] Z. Dong, "Multi-dimensional synergy in ecological governance: a case study of the Yangtze river basin in Hubei province," Hubei Social Sciences, vol. 03, pp. 82-89, 2018, in Chinese.

[10] H. Zhu, "Study on ecological management model and countermeasures of Qinghai lake basin," Qinghai Social Sciences, no. 6, pp. 94-98, 2012, in Chinese.

[11] H. Shi, M. Zhao, F. A. Aregay, K. Zhao, and Z. Jiang, "Residential environment induced preference heterogeneity for river ecosystem service improvements: a comparison between urban and rural households in the Wei river basin, China," Discrete Dynamics in Nature and Society, vol. 20169 pages, 2016.

[12] Z. Xi-qun, "Multiple coordination of ecological governance: a case study of Taihu river basin," Reform, no. 2, pp. 96-107, 2017, in Chinese.

[13] China Water Economic Research Institute, Guidelines for Social Evaluation of Water Conservancy Construction Projects, China Water \& Power Press, Beijing, China, 1999, in Chinese.

[14] L. Jian, Z. Hui-bo, and X. Hui, "Co-governance of multiple small collective: the economic logic of river valley's ecological governance," Chinese Journal of Population, Resources and Environment, vol. 22, no. 12, pp. 26-31, 2012, in Chinese.

[15] L. Lohmann, "Toward a different debate in environmental accounting: the cases of carbon and cost-benefit," Accounting, Organizations and Society, vol. 34, no. 3-4, pp. 499-534, 2009.

[16] L. Xue-song and S. Bo-wen, "Evaluation on comprehensive benefits of urban water environment governance based on AHP: an example on wuhan," Areal Research and Development, vol. 32, no. 4, pp. 171-176, 2013, in Chinese. 
[17] X. Zhi-gang, M. Rui, Y. Xiu-bo, J. Lu-guang, and W. Yi, "Cost effectiveness, policy mechanism and sustainable development of ecological restoration: evaluationon ecological protection \& construction projects and policy in China from a Holistic perspective," China Soft Science, no. 2, pp. 5-13, 2010, in Chinese.

[18] J. B. Wiener, "Eco-environmental risk management," International Cooperation on Environment and Development, Beijing, China, 2015.

[19] Y. Yan, Y. Liu-yang, X. Tao, and Z. Min-juan, "Public preferences and policy evaluation of air pollution control: taking the haze governance in Xi'an as an example," Journal of Arid Land Resources and Environment, vol. 32, no. 4, pp. 19-25, 2018, in Chinese.

[20] N. Beharry-Borg and R. Scarpa, "Valuing quality changes in Caribbean coastal waters for heterogeneous beach visitors," Ecological Economics, vol. 69, no. 5, pp. 1124-1139, 2010.

[21] H. Fan and M. J. Zhao, "Choice experiments for natural resource non-market evaluation," Resources Science, vol. 35, no. 7, pp. 1347-1354, 2013, in Chinese.

[22] D. McFadden, "Conditional logit analysis of qualitative choice behavior," in Frontiers in Econometrics, P. Zarembka, Ed., Academic Press, New York, NY, USA, 1973.

[23] D. Hensher, N. Shore, and K. Train, "Households' willingness to pay for water service attributes," Environmental \& Resource Economics, vol. 32, no. 4, pp. 509-531, 2005.

[24] E. Doherty and D. Campbell, "Demand for improved food safety and quality: a cross-regional comparison," in Proceedings of the Selected Paper from 85th Annual Conference of the Agricultural Economics Society, Warwick, UK, 2011.

[25] M. Stithou, S. Hynes, N. Hanley et al., "Estimating the value of achieving "good ecological status" in the boyne river catchment in Ireland using choice experiments," The Economic and Social Review, vol. 43, no. 3, pp. 397-422, 2012.

[26] Y. Z. Tan, J. Chen, Q. R. Wang et al., "Estimation of nonmarket value of prime farmland based on choice experiment model," Journal of Natural Resources, vol. 27, no. 11, pp. 1981-1994, 2012, in Chinese.

[27] G. Ya-zhen, H. Wei, M. Bennett, and Q. Huan-guang, "Study on eco-compensation policy design for wetland: a choice experiment approach," Journal of Natural Resources, vol. 31, no. 2, pp. 241-251, 2016, in Chinese.

[28] M. A. Weber and S. Stewart, "Public values for river restoration options on the middle Rio Grande," Restoration Ecology, vol. 17, no. 6, pp. 762-771, 2009.

[29] K. K. Zander, R. Parkes, A. Straton et al., "Water ecosystem services in northern Australia--how much are they worth and who should pay for their provision?" PLoS One, vol. 8, no. 5, Article ID e64411, 2013.

[30] Z. Minjuan, X. Tao, S. Hengtong, Y. Liuyang, L. Bingyang, and L. Qian, "Ecosystem service valuation of watershed restoration in the Shiyang river basin under heterogeneous preferences," Journal of Resources and Ecology, vol. 6, no. 6, pp. 405-411, 2015.

[31] W. Y. Chen, I. Liekens, and S. Broekx, "Identifying societal preferences for river restoration in a densely populated urban environment: evidence from a discrete choice experiment in central brussels," Environmental Management, vol. 60, no. 2, pp. 263-279, 2017.

[32] X. Tao, Z. Min-juan, and Q. Dan, "Ecological system restoration benefits evaluation of the continental river system in northwestern China: based on the Heihe river basin," Journal of Nanjing Agricultural University (Social Sciences Edition), vol. 18, no. 4, pp. 127-136, 2018, in Chinese.
[33] P. Da Costa and D. Hernandez, "The economic value of ecosystem conservation: a discrete choice experiment at the Taravo river basin in corsica," 2019, https://hal.archivesouvertes.fr/hal-01971681.

[34] W. Adamowicz, P. Boxall, M. Williams, and J. Louviere, "Stated preference approaches for measuring passive use values: choice experiments and contingent valuation," American Journal of Agricultural Economics, vol. 80, no. 1, pp. 64-75, 1998.

[35] D. A. Hensher, J. M. Rose, and W. H. Greene, "Combining RP and SP data: biases in using the nested logit "trick" - contrasts with flexible mixed logit incorporating panel and scale effects," Journal of Transport Geography, vol. 16, no. 2, pp. 126-133, 2008.

[36] D. A. Hensher and W. H. Greene, "The mixed logit model: the state of practice," Transportation, vol. 30, no. 2, pp. 133-176, 2003.

[37] K. Train, Discrete Choice Methods with Simulation, Cambridge University Press, Cambridge, UK, 2003.

[38] M. Morrison, J. Bennett, R. Blamey, and J. Louviere, "Choice modeling and tests of benefit transfer," American Journal of Agricultural Economics, vol. 84, no. 1, pp. 161-170, 2002.

[39] L. Yao, M. Zhao, and T. Xu, "China's water-saving irrigation management system: policy, implementation, and challenge," Sustainability, vol. 9, no. 12, p. 2339, 2017.

[40] S. Kang, X. Su, L. Tong et al., "The impacts of human activities on the water-land environment of the Shiyang River basin, an arid region in northwest China," Hydrological Sciences Journal, vol. 49, no. 3, 2004.

[41] J. Yu-ting, Study on Water Resources Governance Policy of the Shiyang River Basin, Lanzhou University, Lanzhou, China, 2016, in Chinese.

[42] W. F. Kuhfeld, "Experimental design, efficiency, coding, and choice designs," Marketing Research Methods in Sas: Experimental Design, Choice, Conjoint, and Graphical Techniques, pp. 47-97, 2005.

[43] T. Xu, Y. Liu-yang, D. Qiao, L. qian, Y. Yan, and Z. Min-juan, "Social and ecological benefits evaluation of water-saving irrigation technology adoption in Minqin County," Resources Science, vol. 38, no. 10, pp. 1925-1934, 2016, in Chinese.

[44] J. M. Rose, M. C. J. Bliemer, D. A. Hensher, and A. T. Collins, "Designing efficient stated choice experiments in the presence of reference alternatives," Transportation Research Part B: Methodological, vol. 42, no. 4, pp. 395-406, 2008.

[45] F. R. Johnson, E. Lancsar, D. Marshall et al., "Constructing experimental designs for discrete-choice experiments: report of the ISPOR conjoint analysis experimental design good research practices task force," Value in Health, vol. 16, no. 1, pp. 3-13, 2013.

[46] R. J. Johnston, E. T. Schultz, K. Segerson, E. Y. Besedin, and M. Ramachandran, "Enhancing the content validity of stated preference valuation: the structure and function of ecological indicators," Land Economics, vol. 88, no. 1, pp. 102-120, 2012.

[47] S. Heng-tong and Z. Min-juan, "Willingness to pay differences across ecosystem services and total economic valuation based on choice experiments approach," Resources Science, vol. 37, no. 2, pp. 351-359, 2015, in Chinese.

[48] F. Aregay, L. Yao, and M. Zhao, "Spatial preference heterogeneity for integrated river basin management: the case of the Shiyang river basin, China," Sustainability, vol. 8, no. 10, p. 970, 2016.

[49] F. Terris-Prestholt, N. Neke, J. M. Grund et al., "Using discrete choice experiments to inform the design of complex interventions," Trials, vol. 1, no. 20, pp. 1-11, 2019. 
[50] S. Sun, W. Hu, and P. Qing, "Comparative price in choice experiments: the effects of price information on willingness to pay," in Proceedings of the Agricultural and Applied Economics Association, Atlanta, GA, USA, July 2019.

[51] J. M. Duke, A. M. Borchers, R. J. Johnston, and S. Absetz, "Sustainable agricultural management contracts: using choice experiments to estimate the benefits of land preservation and conservation practices," Ecological Economics, vol. 74, pp. 95-103, 2012.

[52] D. L. Ortega, H. H. Wang, N. J. O. Widmar et al., "Chinese producer behavior: aquaculture farmers in southern China, selected paper," in Proceedings of the Agricultural \& Applied Economics Association's 2013 AAEA \& CAES Joint Annual Meeting, pp. 4-6, Washington, DC, USA, August 2013. 